\title{
(2) OPEN ACCESS \\ Evidence that an intervention weakens the relationship between adolescent electronic cigarette use and tobacco smoking: a 24-month prospective study
}

\author{
Mark Conner $\odot,{ }^{1}$ Sarah Grogan, ${ }^{2}$ Ruth Simms-Ellis, ${ }^{1}$ Keira Flett, ${ }^{3}$ \\ Bianca Sykes-Muskett, ${ }^{1}$ Lisa Cowap, ${ }^{3}$ Rebecca Lawton, ${ }^{1}$ Christopher Armitage, ${ }^{4}$ \\ David Meads, ${ }^{5}$ Laetitia Schmitt, ${ }^{6}$ Carole Torgerson, ${ }^{7}$ Robert West, ${ }^{5}$ Kamran Siddiqi ${ }^{8}$
}

School of Psychology, University of Leeds, Leeds, UK 2Department of Psychology, Manchester Metropolitan University, Manchester, UK ${ }^{3}$ Faculty of Health Sciences, Staffordshire University, Staffordshire, UK

${ }^{4}$ Psychology, University of Manchester, Manchester, UK 5 Institute of Health Sciences, University of Leeds, Leeds, UK ${ }^{6}$ Academic Centre for Health Economics, University of York, York, UK

${ }^{7}$ Education, Durham University, Durham, UK

${ }^{8}$ Institute of Health Sciences, University of York, York, UK

\section{Correspondence to}

Professor Mark Conner, School of Psychology, University of Leeds, Leeds LS2 9JT, UK: m.t.conner@leeds.ac.uk

Received 20 December 2018 Revised 3 May 2019

Accepted 25 May 2019 Published Online First 28 June 2019

\begin{abstract}
Background The electronic cigarette (e-cigarette) use to subsequent smoking relationship in adolescents has received much attention. Whether an intervention to reduce smoking initiation attenuated this relationship was assessed.

Method Data were from 3994 adolescent never smokers (aged 13-14 years at baseline) as part of a cluster randomised controlled trial. Self-report measures of smoking, e-cigarette use and covariates were assessed and used to predict ever smoked cigarettes, any recent tobacco smoking and regularly smoked cigarettes at 24-month follow-up.

Results Baseline ever use of e-cigarettes was associated with ever smoked cigarettes $(\mathrm{OR}=4.03$, $95 \% \mathrm{Cl} 3.33$ to 4.88; controlling for covariates, $\mathrm{OR}=2.78,95 \% \mathrm{Cl} 2.20$ to 3.51$)$, any recent tobacco smoking $(\mathrm{OR}=3.38,95 \% \mathrm{Cl} 2.72$ to 4.21 ; controlling for covariates, $\mathrm{OR}=2.17,95 \% \mathrm{Cl} 1.76$ to 2.69$)$ and regularly smoked cigarettes $(\mathrm{OR}=3.60,95 \% \mathrm{Cl} 2.35$ to 5.51; controlling for covariates, $O R=1.27,95 \% \mathrm{Cl}$ 1.17 to 1.39) at follow-up. For ever smoked cigarettes only, the impact of e-cigarette use was attenuated in the intervention $(O R=1.83)$ compared with control $(\mathrm{OR}=4.53)$ condition. For ever smoked cigarettes and any recent tobacco smoking, the impact of e-cigarette use was attenuated among those with friends who smoked ( $\mathrm{OR}=2.05$ (ever smoked); 1.53 (any tobacco use)) compared with those without friends who smoked $(\mathrm{OR}=3.32$ (ever smoked); 2.17 (any tobacco use)).

Conclusions This is one of the first studies to show that e-cigarette use was robustly associated with measures of smoking over 24 months and the first to show an intervention to attenuate the relationship. Further research with a broader age range of adolescents is required.
\end{abstract}

\section{INTRODUCTION}

The potential beneficial impact of electronic cigarettes (e-cigarettes) on quitting cigarette smoking has been identified. ${ }^{1-4}$ At the same time, the increasing use of e-cigarettes in adolescents (particularly in those who do not smoke) has raised concerns. A focus of attention has been on the role of e-cigarettes in smoking initiation. Recent cross-sectional surveys of cohorts in both the USA ${ }^{5-8}$ and $\mathrm{UK}^{9-11}$ have shown that adolescents' rates of ever use of e-cigarettes increased at the same time that rates of cigarette use decreased. In contrast, longitudinal surveys in adolescents show use of e-cigarettes to be associated with subsequent smoking initiation. For example, US studies show e-cigarette use to be positively associated with initiation of smoking 12-24 months later in 14-16-year olds. ${ }^{12-15}$ Similar results have been reported in UK studies ${ }^{16}$ of 14-year olds over the periods of 12 months.

The present research reports post-hoc analysis of a subset of data from a cluster randomised controlled trial of an intervention on reducing smoking in 16-year olds. ${ }^{18} 19$ This intervention significantly reduced ever smoking and any recent tobacco use but had mixed effects on regular smoking and breath carbon monoxide. ${ }^{19}$ Here, we analysed data from adolescents who were never smokers and either ever or never users of e-cigarettes at age 14 . The focus was on predicting smoking at age 16 (24 months later). A previous paper reported the impact of e-cigarette use at age 14 among never smokers on smoking at age 15 (12 months later) in the control condition. ${ }^{16}$ The present study aimed to extend knowledge in this area in four important ways. First, this is the first study to examine the effects of an intervention designed to reduce adolescent smoking initiation on relationships between e-cigarette use and subsequent smoking. Second, this study explored associations over longer periods of time, doubling the most commonly reported follow-up period of 12 months (24 months, age 14 at baseline, age 16 at follow-up). Third, this study assessed the impact beyond any smoking postbaseline to examine any recent tobacco smoking and regular smoking at follow-up (only Barrington-Trimis et $a l^{15}$ report data on regular smoking). Fourth, selfreported measures of smoking at follow-up were validated against objective smoking measures (see $\mathrm{e}^{16}$ for similar approach).

In summary, the present research assessed relationships between e-cigarette use and smoking (objectively validated) 24 months later in a sample of UK adolescents aged 14 at baseline. Moderating effects of an intervention and effects of controlling for a number of covariates (gender, ethnicity, individual/school level socioeconomic status, friends and family smoking, impulsivity and intentions, attitudes, norms, perceived behavioural control and self-efficacy in relation to smoking) were also 
assessed. No previous study has examined the impact of an intervention designed to reduce smoking initiation ${ }^{18}{ }^{19}$ on relationships between e-cigarette use and subsequent smoking. The moderating effect of friends smoking was also explored. Two previous UK studies ${ }^{16}$ had shown the impact of e-cigarettes on subsequent smoking initiation to be significantly stronger in those with no friends who smoked compared those with friends who smoke.

\section{METHODS}

\section{Participants and procedures}

Data were collected as part of a preregistered, 4-year cluster randomised controlled trial (RCT) of a school-based intervention to prevent smoking initiation ${ }^{18}{ }^{19}$ using implementation intentions. ${ }^{20-22}$ The study was conducted in 45 schools in England with adolescents initially aged 11-12 years. Those in intervention schools (coded 1) read antismoking messages and formed implementation intentions about how to refuse offers of cigarettes on eight occasions (twice per year), for example, "If offered a cigarette, I will say... no cancer sticks for me". Those in control schools (coded 0) formed implementation intentions in relation to completing homework. Head teachers consented to school participation with parents given option to withdraw children from the study. Adolescents consented by completing questionnaires matched across time points by code. The cluster RCT $^{19}$ showed that formation of implementation intentions in relation to cigarette offers significantly reduced ever smoking cigarettes and any combustible tobacco use in the last 30 days but not regular cigarette smoking or breath carbon monoxide levels at follow-up. The data reported here are from waves 3 (September-December 2014; referred to as baseline in 13-14year olds) and 5 (September-December 2016; referred to as follow-up in 15-16-year olds) of the trial when e-cigarette use measures were added to the data collection. Only respondents reporting having never smoked a cigarette at baseline were included here (ie, this is a post-hoc analysis). A previous study reported the impact of e-cigarette use (wave 3) on smoking 12 months later (wave 4 ) in the control condition. ${ }^{16}$

The University of Leeds, UK (Faculty of Medicine) ethical review committee approved the study (reference 12-0155).

\section{Measures}

Cigarette use was assessed using standardised measures ${ }^{23}$ at both time points; adolescents ticked one of: 'I have never smoked; I have only tried smoking once; I used to smoke sometimes, but I never smoke cigarettes now; I sometimes smoke cigarettes now, but I don't smoke as many as one a week; I usually smoke between one and six cigarettes a week and I usually smoke more than six cigarettes a week'. Only respondents marking the first response at baseline were retained for analysis. At follow-up, this measure was converted into a measure of ever smoked cigarettes (first response coded 0; other responses coded 1) and regularly smoked cigarettes (last two responses coded 1; other responses coded 0 ). At follow-up only, respondents indicated on how many days in the last 30 they had used (tobacco) cigarettes, cigars, pipes and sheesha (flavoured tobacco); converted to a measure of any recent tobacco smoking (no days smoking $=0$; one or more days smoking=1). The self-reported smoking measures at follow-up were validated against a measure of breath carbon monoxide (CO) levels (Micro+Smokerlyzer CO Monitor, Bedfont Scientific Limited, Kent, England), although we did not reclassify selfreport measures based on CO level. Such measures are reliable and valid ways of assessing regular cigarette smoking ${ }^{24} 25$ but not occasional smoking due to the short half-life (4-6 hours) of breath $\mathrm{CO}$.

E-cigarettes/vapourisers were described as 'a tube that sometimes looks like a normal cigarette and has a glowing tip. They all puff a vapour that looks like smoke but unlike normal cigarettes, they don't burn tobacco'. Use of e-cigarettes at baseline was tapped by one item ('Which ONE of the following is closest to describing your experience of e-cigarettes or vapourisers', I have never used them; I have tried them once or twice; I use them sometimes (more than once a month but less than once a week); I use them often (more than once a week)'), converted into a measure of ever used e-cigarettes (first response $=0$; other responses $=1$ ).

Other measures were assessed as covariates/moderators. Demographic variables included gender $($ boy $=0 ;$ girl $=1)$, ethnicity (non-white $=0$, white $=1$ ), family affluence (based on the 4-item Family Affluence scale ${ }^{26}$ : scored 0-3, higher scores indicating greater affluence), percentage of children per school eligible for free school meals (<median $20 \%=0 ;>20 \%=1) .{ }^{27}$ Friends' smoking was assessed using the question, 'How many of your friends smoke?', none of them; only a few; half and half; most but not all; all of them (none of them=0; a few or more $=1$ ). Family smoking at baseline was assessed using the question: 'Who smokes in your family now? Tick all the people who smoke at the moment', followed by a list of family members (no family members $=0$; one or more family members $=1$ ). Impulsiveness was measured at follow-up based on a 5-item impulsivity scale (scored $0-5$, higher scores indicating greater impulsivity). ${ }^{28}$

Health cognitions about smoking ${ }^{21}$ were assessed as mean of multiple questions on 5 -point scales: intention (three questions; for example, 'I plan not to smoke'; Cronbach's $\alpha=0 \cdot 90$ ); attitude (seven questions; for example, 'For me, smoking would be... good-bad'; $\alpha=0 \cdot 87$ ); perceived norms (five questions; for example, 'Most of my friends think... I should smoke-I should not smoke'; $\alpha=0.79$ ); perceived behavioural control (three questions; for example, 'I am confident I could resist smoking', strongly disagree-strongly agree; $\alpha=0.69$ ); self-efficacy (six questions; for example, 'I can say no to smoking, even at school' strongly disagree-strongly agree; $\alpha=0 \cdot 91$ ). Questions were highly skewed towards negative views of smoking and so were dichotomised (negative views $=0$; less negative views $=1$ ). Based on previous findings, ${ }^{16} 17$ an interaction between e-cigarette use and friends smoking was also computed.

\section{Data analysis}

Missing data ranged from $0.0 \%$ (gender) to $1.4 \%$ (ethnicity) and $96 \%$ of the 3994 never smokers in the sample would have been available for analysis under the traditional listwise deletion method across variables. Data were missing due to item nonresponse. As level of missing values was low, missing at random was assumed to justify multiple imputation. Multiple imputation in SPSS 24 generated five imputed datasets. Imputed values compared reasonably to observed values, and results using listwise deletion were similar to multiple imputation, so imputed results are presented. SPSS was used to analyse descriptives on all measures, to examine relationships between ever used e-cigarette at baseline and smoking measures at follow-up and validate smoking measures against follow-up breath CO levels (using logistic regressions).

The main analyses used hierarchical linear models HLM $7^{29}$ to predict follow-up ever smoked cigarettes, any recent tobacco smoking or regularly smoked cigarettes based on ever use of 
e-cigarettes and covariates. Model 1 controlled for the clustering of adolescents within schools and used baseline ever use of e-cigarettes as a predictor. Model 2 added covariates, and model 3 tested interactions between condition and each covariate (crosslevel interaction). All multilevel analyses used random slopes and population average model with robust SEs. Analyses were conducted for each of five imputed datasets, and the results combined using Rubin's rules. For each predictor, we report the OR, 95\% CI and p value. We also report the -2 log-likelihood to indicate model fit. When significant, we decomposed the interaction between e-cigarette use and friends smoking using the free software provided by Preacher (model 1; http://www. quantpsy.org/interact/hlm2.htm). For significant cross-level interactions between intervention condition and predictors of smoking, we compared the effects for predictors estimated separately in control and intervention conditions.

\section{RESULTS}

\section{Sample description}

Table 1 provides descriptive data on all measures for the full imputed sample. At baseline, the sample of 3994 never smokers (table 1) comprised $47.7 \%$ males, with a majority $(81.0 \%)$ not having ever used e-cigarettes. At follow-up, 24 months later, $20.3 \%$ had ever smoked cigarettes, 9.7\% reported any recent tobacco smoking, while $2.1 \%$ regularly smoked cigarettes (table 1). At follow-up, breath CO levels were significantly higher in those reporting ever versus never having smoked cigarettes $(p<0.001)$, in those reporting one or more versus zero days any recent tobacco smoking $(\mathrm{p}<0.001)$ and in regularly smoked cigarettes versus other groups $(p<0.001)$.

\section{Simple relationships between baseline use of e-cigarettes and follow-up smoking}

Table 2 shows the numbers reporting different levels of smoking cigarettes or any recent tobacco smoking at follow-up split by baseline ever used e-cigarette. Ever smoked cigarettes at follow-up was $15.2 \%(492 / 3235)$ for those not using versus $42.4 \%(322 / 759)$ for those ever using e-cigarettes at baseline. The figures for any recent tobacco smoking was 7.0\% (226/3236) for those not using versus $21.2 \%$ (161/758) for those ever using e-cigarettes at baseline. Regularly smoked cigarettes at follow-up was $1.5 \%$ (47/3235) for those not using versus 4.9\% (37/759) for those ever using e-cigarettes at baseline. More frequent e-cigarette use (at least once per month) at baseline was relatively rare, although more frequent use did appear to be more strongly associated with the three follow-up smoking measures (table 2).

\section{Prospective analyses}

Ever smoked cigarettes at follow-up (table 3, left-hand panel) was significantly predicted by baseline ever used e-cigarettes (model 1; OR $=4.03, \mathrm{p}<0.001$ ). It was attenuated but remained significant when controlling for covariates (model 2; $\mathrm{OR}=2.78$, $\mathrm{p}<0.001)$. Ever smoked cigarettes was significantly higher in adolescents who were ever users of e-cigarettes, female, nonwhite, had friends who smoked, more impulsive, had more positive attitudes and perceived behavioural control about smoking and in the control condition. There was also a significant interaction between ever used e-cigarettes and friends smoking (model 2 ; $\mathrm{OR}=0.72, \mathrm{p}<0.05)$. Decomposition of this interaction indicated that the impact of ever used e-cigarettes on subsequent ever smoking initiation was greater in those with no friends who smoked $(\mathrm{OR}=4.23,95 \%$ CI 3.19 to $5.61, \mathrm{p}<0.001)$ compared with those with one or more friends who smoked $(\mathrm{OR}=2.58$,
Table 1 Descriptive data for the sample $(n=3994)$

(\%)

\begin{tabular}{|c|c|}
\hline \multicolumn{2}{|l|}{ Gender } \\
\hline Male & $1904(47.7)$ \\
\hline Female & $2090(52.3)$ \\
\hline \multicolumn{2}{|l|}{ Ethnicity } \\
\hline White & $688(17.2)$ \\
\hline Non-white & $3306(82.8)$ \\
\hline Family affluence1 & $2.72(0.49)$ \\
\hline \multicolumn{2}{|c|}{ Ever used e-cigarettes (baseline) } \\
\hline No & $3236(81.0)$ \\
\hline Yes & $758(19.0)$ \\
\hline \multicolumn{2}{|l|}{ Friend smokers } \\
\hline None & $2602(65.1)$ \\
\hline A few or more & $1392(34.9)$ \\
\hline \multicolumn{2}{|l|}{ Family smokers } \\
\hline None & $1502(37.6)$ \\
\hline One or more & $2492(62.4)$ \\
\hline Impulsivity* & $2.04(1.65)$ \\
\hline \multicolumn{2}{|l|}{ Intention } \\
\hline Low & $3624(90.7)$ \\
\hline High & $370(9.3)$ \\
\hline \multicolumn{2}{|l|}{ Attitude } \\
\hline Low & $3302(82.7)$ \\
\hline High & $692(17.3)$ \\
\hline \multicolumn{2}{|l|}{ Norms } \\
\hline Low & $3455(86.5)$ \\
\hline High & $539(13.5)$ \\
\hline \multicolumn{2}{|c|}{ Perceived behavioural control } \\
\hline Low & $3260(81.6)$ \\
\hline High & $734(18.4)$ \\
\hline \multicolumn{2}{|l|}{ Self-efficacy } \\
\hline Low & 3239 (81.1) \\
\hline High & $755(18.9)$ \\
\hline \multicolumn{2}{|c|}{ Free school meals $\dagger$} \\
\hline Low & $22(48.9)$ \\
\hline High & $23(51.1)$ \\
\hline \multicolumn{2}{|l|}{ Conditiont } \\
\hline Control & $20(44.4)$ \\
\hline Intervention & $25(55.6)$ \\
\hline \multicolumn{2}{|c|}{ Ever smoked cigarettes (follow-up) } \\
\hline No & $3180(79.6)$ \\
\hline Yes & $814(20.4)$ \\
\hline \multicolumn{2}{|c|}{ Any recent tobacco smoking (follow-up) } \\
\hline No & $3607(90.3)$ \\
\hline Yes & $387(9.7)$ \\
\hline \multicolumn{2}{|c|}{ Regularly smoked cigarettes (follow-up) } \\
\hline No & 3910 (97.9) \\
\hline Yes & $84(2.1)$ \\
\hline
\end{tabular}

${ }^{*}$ Mean and SD for these variables.

tNumber of schools.

95\% CI 2.05 to 3.24, p<0.001). Analyses (model 3) revealed that condition significantly moderated the impact of e-cigarette smoking $(\mathrm{OR}=0.50,95 \% \mathrm{CI} 0.33$ to $0.74, \mathrm{p}<0.001)$ and the interaction between ever used e-cigarettes and friends' smoking 
Table 2 Relationships between e-cigarette use at baseline (aged 13-14 years) and smoking cigarettes or any combustible tobacco 24 months later (aged 15-16 years) among those who were never smokers at baseline $(n=3994)$

\begin{tabular}{|c|c|c|c|c|}
\hline \multirow{3}{*}{$\begin{array}{l}\text { Smoking at age 15-16 } \\
\text { years }\end{array}$} & \multicolumn{4}{|c|}{ Baseline e-cigarette use } \\
\hline & Never & Tried & Infrequent & Frequent \\
\hline & & (1-2 times) & (1/month-1/week) & (>1/week) \\
\hline & n (\%) & n (\%) & n (\%) & n (\%) \\
\hline \multicolumn{5}{|l|}{ Cigarette smoking } \\
\hline Never & $2743(68.7)$ & $405(10.1)$ & $30(0.8)$ & $2(0.1)$ \\
\hline Once & $285(7.2)$ & $147(3.7)$ & $11(0.3)$ & $1(0.0)$ \\
\hline Used to smoke & $89(2.2)$ & $63(1.6)$ & $8(0.2)$ & $5(0.1)$ \\
\hline Rarely (<1/week) & $72(1.8)$ & $44(1.1)$ & $5(0.1)$ & $1(0.0)$ \\
\hline Occasional (1-6/week) & $21(0.5)$ & $18(0.5)$ & $1(0.0)$ & $0(0.0)$ \\
\hline Frequent (>6/week) & $25(0.6)$ & $12(0.3)$ & $6(0.2)$ & $0(0.0)$ \\
\hline \multicolumn{5}{|c|}{ Any recent tobacco smoking } \\
\hline None & $3010(75.4)$ & $556(13.9)$ & $37(0.9)$ & $4(0.1)$ \\
\hline One or more days & $226(5.7)$ & $133(3.3)$ & $23(0.6)$ & $5(0.1)$ \\
\hline
\end{tabular}

(OR=1.70, 95\% CI 1.01 to $2.88, \mathrm{p}<0.05)$. Decomposition of the moderation effect for condition indicated that the impact of ever used e-cigarettes on likelihood of ever smoked cigarettes was attenuated in the intervention $(\mathrm{OR}=1.83,95 \%$ CI 1.35 to $2.48, \mathrm{p}<0.001)$ compared with the control $(\mathrm{OR}=4.53,95 \% \mathrm{CI}$ 3.41 to $6.03, p<0.001)$ condition. The interaction between ever used e-cigarettes and friends' smoking became non-significant in the intervention condition $(\mathrm{OR}=0.99,95 \% \mathrm{CI} 0.66$ to 1.47 , $\mathrm{p}>0.05)$ but remained significant in the control condition $(\mathrm{OR}=0.46,95 \% \mathrm{CI} 0.33$ to $0.64, \mathrm{p}<0.001)$, reflecting the fact that ever used e-cigarettes had a stronger effect among those with no friends who smoked.

In relation to any recent tobacco smoking at follow-up (table 3 , middle panel), smoking was significantly predicted by baseline ever used e-cigarettes (model $1 ; \mathrm{OR}=3.38, \mathrm{p}<0.001$ ) and attenuated but remained significant when controlling for covariates (model 2; $\mathrm{OR}=2.17, \mathrm{p}<0.001$ ). Recent smoking was significantly higher in adolescents who at baseline were ever users of e-cigarettes, female, non-white, had lower family affluence, had

Table 3 Association of ever used cigarettes (left-hand panel), any recent tobacco smoking (middle panel) or regular smoker (right-hand panel) at follow-up with predictors among never users of combustible cigarettes at baseline (over 24 months; $n=3994$ )

\begin{tabular}{|c|c|c|c|c|c|c|}
\hline \multirow[b]{2}{*}{ Predictors } & \multicolumn{2}{|c|}{ Ever smoked cigarettes } & \multicolumn{2}{|c|}{ Any recent tobacco smoking } & \multicolumn{2}{|c|}{ Regularly smoked cigarettes } \\
\hline & $\begin{array}{l}\text { OR } \\
(95 \% \mathrm{Cl})\end{array}$ & $P$ value & $\begin{array}{l}\text { OR } \\
(95 \% \mathrm{Cl})\end{array}$ & $P$ value & $\begin{array}{l}\text { OR } \\
(95 \% \mathrm{Cl})\end{array}$ & $P$ value \\
\hline \multicolumn{7}{|l|}{ Model 1 without covariates } \\
\hline Never used e-cigarettes & 1.00 & & 1.00 & & 1.00 & \\
\hline Ever used e-cigarettes & 4.03 (3.33 to 4.88$)$ & $<0.001$ & 3.38 (2.72 to 4.21$)$ & $<0.001$ & 3.60 (2.35 to 5.51$)$ & $<0.001$ \\
\hline \multicolumn{7}{|l|}{ Model 2 with covariates } \\
\hline Never used e-cigarettes & 1.00 & & 1.00 & & 1.00 & \\
\hline Ever used e-cigarettes & 2.78 (2.20 to 3.51$)$ & $<0.001$ & 2.17 (1.76 to 2.69$)$ & $<0.001$ & 1.27 (1.17 to 1.39$)$ & $<0.001$ \\
\hline Male & 1.00 & & 1.00 & & 1.00 & \\
\hline Female & 1.41 (1.29 to 1.54$)$ & $<0.001$ & 1.16 (1.08 to 1.25$)$ & $<0.001$ & 1.08 (1.04 to 1.12 ) & $<0.001$ \\
\hline Ethnicity=non-white & 1.00 & & 1.00 & & 1.00 & \\
\hline Ethnicity=white & 0.81 ( 0.68 to 0.98 & $<0.05$ & $0.59(0.50$ to 0.70$)$ & $<0.001$ & 0.91 (0.85 to 0.98 ) & $<0.05$ \\
\hline Low family affluence & 1.00 & & 1.00 & & 1.00 & \\
\hline High family affluence & 0.92 (0.83 to 1.03$)$ & $>0.05$ & 0.89 (0.80 to 0.98$)$ & $<0.05$ & 0.88 (0.82 to 0.93 ) & $<0.001$ \\
\hline Free school meals=low & 1.00 & & 1.00 & & 1.00 & \\
\hline Free school meals=high & 1.12 (0.93 to 1.35$)$ & $>0.05$ & 1.10 (0.97 to 1.24$)$ & $>0.05$ & 1.03 (0.96 to 1.10$)$ & $>0.05$ \\
\hline Friend smokers=none & 1.00 & & 1.00 & & 1.00 & \\
\hline Friend smokers=more than none & 1.49 (1.28 to 1.72$)$ & $<0.001$ & 1.53 (1.33 to 1.76$)$ & $<0.001$ & 1.03 (0.97 to 1.10$)$ & $>0.05$ \\
\hline Family smokers=none & 1.00 & & 1.00 & & 1.00 & \\
\hline Family smokers=one or more & 1.10 (0.99 to 1.22$)$ & $>0.05$ & 1.07 (0.99 to 1.17$)$ & $>0.05$ & 0.95 (0.91 to 1.00$)$ & $>0.05$ \\
\hline Impulsivity & 1.30 (1.26 to 1.35$)$ & $<0.001$ & 1.23 (1.19 to 1.26$)$ & $<0.001$ & 1.03 (1.01 to 1.05$)$ & $<0.01$ \\
\hline Intentions=low & 1.00 & & 1.00 & & 1.00 & \\
\hline Intentions=high & 1.58 (1.24 to 2.02$)$ & $<0.001$ & 1.24 (1.00 to 1.54$)$ & $>0.05$ & 1.12 (0.98 to 1.29$)$ & $>0.05$ \\
\hline Attitude=low & 1.00 & & 1.00 & & 1.00 & \\
\hline Attitude=high & 1.18 (1.05 to 1.33$)$ & $<0.01$ & 1.21 (1.04 to 1.41$)$ & $<0.05$ & 0.98 (0.92 to 1.06$)$ & $>0.05$ \\
\hline Perceived norms=low & 1.00 & & 1.00 & & 1.00 & \\
\hline Perceived norms=high & 1.02 (0.88 to 1.19$)$ & $>0.05$ & 1.11 (0.93 to 1.33$)$ & $>0.05$ & 1.15 (1.06 to 1.24$)$ & $<0.01$ \\
\hline Perceived behavioural control=low & 1.00 & & 1.00 & & 1.00 & \\
\hline Perceived behavioural control=high & $1.18(1.02$ to 1.37$)$ & $<0.05$ & $>0.05$ (0.94 to 1.18$)$ & $>0.05$ & 1.08 (1.02 to 1.15$)$ & $<0.01$ \\
\hline Self-efficacy=low & 1.00 & & 1.00 & & 1.00 & \\
\hline Self-efficacy=high & 1.15 (0.98 to 1.35$)$ & $>0.05$ & $1.19(0.89$ to 1.40$)$ & $>0.05$ & 1.01 (0.93 to 1.10$)$ & $>0.05$ \\
\hline Friends smoking $\times$ e-cigarette use & 0.74 (0.62 to 0.88$)$ & $<0.05$ & $0.70(0.53$ to 0.93$)$ & $<0.01$ & 0.90 (0.81 to 1.01$)$ & $>0.05$ \\
\hline Control condition & 1.00 & & 1.00 & & 1.00 & \\
\hline Intervention condition & 0.72 (0.61 to 0.86$)$ & $<0.001$ & $0.86(0.76$ to 0.96$)$ & $<0.05$ & 0.99 (0.93 to 1.05$)$ & $>0.05$ \\
\hline
\end{tabular}


friends who smoked, more impulsive, had more positive attitudes about smoking and in the control condition. There was also a significant interaction between ever used e-cigarettes and friends smoking (model 2; OR=0.70, $\mathrm{p}<0.01$ ). Decomposition of this interaction indicated that the impact of ever used e-cigarettes on subsequent any recent tobacco smoking was greater in those with no friends who smoked (OR=3.96, 95\% CI 2.94 to $5.33, \mathrm{p}<0.001)$ compared with those with one or more friends who smoked (OR=2.07, 95\% CI 1.58, to $2.72, \mathrm{p}<0.001)$. Analyses (model 3) did not reveal any significant moderating effects of condition on relationships between predictors and recent smoking.

Finally, in relation to regularly smoked cigarettes at follow-up (table 3, right-hand panel), smoking was significantly predicted by baseline ever used e-cigarettes (model 1; OR=3.60, $\mathrm{p}<0.001$ ) and was attenuated but remained significant when controlling for covariates (model 2; $\mathrm{OR}=1.27, \mathrm{p}<0.001$ ). Regularly smoked cigarettes was significantly higher in adolescents who were ever users of e-cigarettes, female, non-white, had low family affluence, more impulsive, had more positive norms and perceived behavioural control about smoking. There was no significant interaction between ever used e-cigarettes and friends smoking on regular smoking (model 2; $\mathrm{OR}=0.90, \mathrm{p}>0.05$ ). Analyses (model 3) did not reveal any significant moderating effects of condition on relationships between predictors and regularly smoked cigarettes.

\section{DISCUSSION}

The present research showed that never smoking 14-year olds who ever versus never used e-cigarettes were more likely to report having smoked at least once or more regularly 24 months later. These effects remained (although attenuated) when controlling for various predictors of smoking. The degree of attenuation was greater for regular smoking than for other smoking measures. This study adds to the growing number of US ${ }^{12-15}$ and $\mathrm{UK}^{1617}$ studies showing that e-cigarette use in adolescents is reliably associated with subsequent smoking. The current results are comparable to those reported in a recent meta-analysis of nine such studies (OR=3.50, 95\% CI 2.38 to 5.16) for ever smoking based on comparing never versus ever users of e-cigarettes. ${ }^{30}$ The reviewed studies were generally over a period of 12 months (five of nine studies) with a maximum follow-up period of 18 months and focused on ever smoking. In contrast, the present study was over 24 months and showed effects for ever smoking, any recent tobacco smoking and regular cigarette smoking (see ${ }^{15}$ for similar results). Together, these studies suggest that it is unlikely that the high rates of dual use of e-cigarettes and smoking observed in the US ${ }^{5-8}$ and $\mathrm{UK}^{9-11}$ in cross-sectional surveys of adolescents are entirely attributable to cigarette users subsequently taking up e-cigarettes. In our sample, at follow-up approximately one-third $(177 / 585=30.3 \%)$ of those who used both e-cigarettes and cigarettes reported using e-cigarettes first (a further $191 / 585=32.6 \%$ reported using cigarettes first, and the remainder $217 / 585=37.1 \%$ could not remember which they tried first).

Our findings also indicated that the association between ever use of e-cigarettes and subsequent ever smoked cigarettes or any recent tobacco smoking (but not regularly smoked cigarettes) was significantly stronger among adolescents with no friends who smoked, a group usually considered to be less susceptible to smoking initiation. This replicates and extends previous research ${ }^{17}$ and extends our previous findings ${ }^{16}$ to a larger sample over a longer time period. Barrington-Trimis $e t a l^{31}$ reported similar moderation effects for intentions to smoke. This appears inconsistent with the idea that e-cigarette users are more interested in all forms of nicotine use and the fact that e-cigarette use came first is purely coincidental. ${ }^{32}$ Nevertheless, the fact that adolescent smoking is decreasing at the same time as e-cigarette use is increasing ${ }^{5-11} 33$ appears inconsistent with a causal link between e-cigarette use and subsequent smoking.

Importantly, our research showed for the first time that an intervention ${ }^{18} 192122$ designed to reduce smoking initiation in adolescents significantly weakened the impact of ever used e-cigarettes on follow-up ever smoked cigarettes (but not any recent tobacco smoking or regularly smoked cigarettes). This is the first study to investigate the impact of an antismoking intervention on this relationship. Although the ever used e-cigarettes to ever smoked relationship was attenuated in the intervention condition, it remained significant. This relationship was in addition to a main effect of the intervention on lower rates of ever smoked at follow-up. It is also worth noting that the intervention did not cover e-cigarettes or relationships between e-cigarettes and subsequent smoking. ${ }^{18}{ }^{19}$ A more targeted intervention may arguably have been more successful in reducing the ever used e-cigarettes to subsequent smoking association to zero.

Like other similar studies, our research provides only limited insights into the mechanism relating ever use of e-cigarettes to subsequent smoking. This means we need to remain cautious in making policy recommendations based on these findings. Since the start of our work, UK legislation has banned marketing and selling e-cigarettes to minors and UK agencies are required to enforce age of sale, child and tamper proof packaging, display age of sale signage and health warnings on e-cigarette packaging. ${ }^{34}$ Nevertheless, our findings emphasise the value of regulating the marketing/sale of e-cigarettes to minors in countries where such measures are not in place, particularly given that e-cigarette advertising has been shown to reduce perceived harm of occasional cigarette use. ${ }^{35}$

Our study has a number of strengths including a large demographically diverse sample, assessment of effects over 24 months, exploration of effects on ever smoked cigarettes, any recent tobacco smoking and regularly smoked cigarettes, validated self-reported smoking measures, exploration of covariates and particularly the assessment of the impact of an antismoking intervention. There are also weaknesses. First, our self-reported measure of e-cigarette use was not validated against objective measures. Second, we did not distinguish types of e-cigarette use (eg, delivery method, nicotine content). Furthermore, our study is restricted to first-generation e-cigarette devices, which less closely mimic combustible cigarette in their nicotine delivery profile. ${ }^{36}$ Exploring relationships between the use of new generations of e-cigarettes both containing nicotine or not and different flavourings and subsequent smoking is an important issue for further research. Although e-cigarettes with higher levels of nicotine seen in the US are currently prohibited in the UK, a recent report indicated that rechargeable devices with a tank that users can refill with liquid are now the most widely used among 11-18-year olds, with fruit-flavoured liquid being the most popular. ${ }^{9}$ Third, our analyses were restricted to ever use of e-cigarettes due to low rates of regular e-cigarette use at baseline (table 2). Relatedly, there were only 81 regular smokers in our sample at follow-up restricting the power of analyses on regular smoking.

In summary, this is the first study to report the impact of an antismoking intervention on the relationship between ever use of e-cigarettes and subsequent smoking 24 months later among UK adolescents. Despite including a range of covariates, ${ }^{12-17}$ it is 
possible that other third variables (eg, sensation seeking) could have been responsible for the observed relationships. Therefore, while acknowledging that a causal relationship may be plausible, we cannot confirm this based on our findings and the trends observed over the same time period in the UK are inconsistent with such a causal relationship. Future research could seek to disentangle these apparently contrary findings and assess doseresponse relationships between e-cigarette and subsequent smoking over different time periods in broader age ranges of adolescents while controlling for a range of covariates.

\section{What this paper adds}

- Previous research: A growing number of studies (mainly among US and UK adolescents) indicate that self-reported e-cigarette use is associated with subsequent smoking initiation. However, in general, these studies were conducted over relatively short time periods (12 months), focused only on smoking initiation and not on more regular smoking, did not validate their self-reported smoking measures against objective measures and did not examine the impact of smoking prevention interventions.

- Interpretation: The present research replicates previous findings in this area in showing a significant association between e-cigarette use and subsequent smoking initiation. It also shows similar effects for measures of regular smoking. These relationships were observed over a period of 24 months in measures of ever smoked cigarettes, any recent tobacco smoking and regularly smoked cigarettes. The strength of these associations was reduced but remained significant when controlling for various predictors of smoking. Importantly, the present research showed for the first time that an intervention to reduce smoking initiation attenuated the relationship between e-cigarette use and ever smoked cigarettes (although it remained significant). This suggests the value of interventions to reduce smoking initiation even in groups of adolescents who try e-cigarettes first. Similar to recent UK studies, the present data also showed that the relationship between e-cigarette use and ever smoked cigarettes or any recent tobacco smoking was stronger in those with no friends who smoked at baseline (a group usually thought to be at low risk of starting smoking) versus some friends who smoked at the initial time point. These latter findings are more consistent with the view that ecigarette use is a risk factor for smoking initiation than the view that e-cigarette use may simply be a marker for those who would go on to smoke cigarettes even without having tried e-cigarettes. However, it is notable that this moderation effect was not observed for regular smoking.

Acknowledgements The authors thank the trial steering committee (Professor Amanda Amos, Dr lan Cameron, Dr Christopher Gidlow, Dr Thomas Webb) for advice on measuring e-cigarette use.

Contributors $\mathrm{MC}$ had full access to all of the data in the study and takes responsibility for the integrity of the data and the accuracy of the data analysis. Study concept and design: MC, SG, RL, CA, CT, RW and KS. Acquisition, analysis or interpretation of data: MC, SG, RS-E, KF, BS-M, LC, RL, CA, DM, CT, RW and KS. Drafting of the manuscript: MC and SG. Critical revision of the manuscript for important intellectual content: MC, SG, RL, CA, DM, CT, RW and KS. Statistical analysis: MC and RW. Obtained funding: MC, SG, CA, CT, RW and KS. Administrative, technical or material support: RS-E, KF, BS-M and LC. Study supervision: MC, SG, RL and DM.

Funding The research was supported by a grant from the UK Medical Research Council/National Preventive Research Initiative. CA is additionally supported by the National Institue for Health Research Manchester Biomedical Research Centre and the National Insitute of Health Research Greater Manchester Patient Safety Translational Research Centre. All authors report receiving grants from the National Prevention Research Initiative during the study.

Disclaimer The UK Medical Research Council had no role in the design and conduct of the study; collection, management, analysis and interpretation of the data; preparation, review or approval of the manuscript; and the decision to submit the manuscript for publication. The authors of this article affirm that the manuscript is an honest, accurate and transparent account of the study being reported; that no important aspects of the study have been omitted and that any discrepancies from the study as planned (and, if relevant, registered) have been explained.

\section{Competing interests None declared.}

\section{Patient consent for publication Not required.}

Provenance and peer review Not commissioned; externally peer reviewed.

Data availability statement All available data can be obtained by contacting the corresponding author; the study team will retain exclusive use until the publication of major outputs. Data are available upon reasonable request.

Open access This is an open access article distributed in accordance with the Creative Commons Attribution 4.0 Unported (CC BY 4.0) license, which permits others to copy, redistribute, remix, transform and build upon this work for any purpose, provided the original work is properly cited, a link to the licence is given, and indication of whether changes were made. See: https://creativecommons.org/ licenses/by/4.0/.

\section{ORCID iDs}

Mark Conner http://orcid.org/0000-0002-6229-8143

Kamran Siddiqi http://orcid.org/0000-0003-1529-7778

\section{REFERENCES}

1 Public Health England. E-cigarettes: an evidence update. A report commissioned by public health England. Available: https://www.gov.uk/government/uploads/ system/uploads/attachment_data/file/457102/Ecigarettes_an_evidence_update_ A_report_commissioned_by_Public_Health_England_FINAL.pdf [Accessed 7 Dec 2018]

2 Levy DT, Yuan Z, Luo Y, et al. The relationship of e-cigarette use to cigarette quit attempts and cessation: insights from a large, nationally representative U.S. survey. Nicotine Tob Res 2018;20:ntx166:931-9.

3 Zhu S-H, Zhuang Y-L, Wong S, et al. E-cigarette use and associated changes in population smoking cessation: evidence from US current population surveys. BMJ 2017;358

4 Hajek P, Phillips-Waller A, Przulj D, et al. A randomized trial of e-cigarettes versus Nicotine-Replacement therapy. N Engl J Med 2019;380:629-37.

5 Singh T, Arrazola RA, Corey CG, et al. Tobacco use among middle and high school students — United States, 2011-2015. MMWR Morb. Mortal. Wkly. Rep. 2016;65:361-7.

6 Warner KE. Frequency of e-cigarette use and cigarette smoking by American students in 2014. American Journal of Preventive Medicine 2016;51:179-84.

7 Dutra LM, Glantz SA. E-cigarettes and national adolescent cigarette use: 2004-2014. Pediatrics 2017;139:e20162450.

8 Levy DT, Warner KE, Cummings KM, et al. Examining the relationship of vaping to smoking initiation among US youth and young adults: a reality check. Tob Control 2019;28:629-35

9 Action on Smoking and Health (ASH). Use of electronic cigarettes among young people in Great Britain, 2018. Available: www.ash.org.uk/files/documents/ASH_959. pdf [Accessed 7 Dec 2018].

10 Eastwood B, Dockrell MJ, Arnott D, et al. Electronic cigarette use in young people in Great Britain 2013-2014. Public Health 2015:129:1150-6.

11 Office for National Statistics UK. E-cigarette use in Great Britain, 2017. Available: https://www.ons.gov.uk/peoplepopulationandcommunity/healthandsocialcare/ [Accessed 7 Dec 2018].

12 Leventhal AM, Strong DR, Kirkpatrick MG, et al. Association of electronic cigarette use with initiation of combustible tobacco product smoking in early adolescence. JAMA 2015;314:700-7

13 Primack BA, Soneji S, Stoolmiller M, et al. Progression to traditional cigarette smoking after electronic cigarette use among US adolescents and young adults. JAMA Pediatr 2015;169:1018-23.

14 Watkins SL, Glantz SA, Chaffee BW. Association of Noncigarette tobacco product use with future cigarette smoking among youth in the population assessment of tobacco and Health (path) study, 2013-2015. JAMA Pediatr 2018;172:181-7.

15 Barrington-Trimis JL, Kong G, Leventhal AM, et al. E-cigarette use and subsequent smoking frequency among adolescents. Pediatrics 2018;142.

16 Conner M, Grogan S, Simms-Ellis R, et al. Do electronic cigarettes increase cigarette smoking in UK adolescents? Evidence from a 12-month prospective study. Tob Control 2018;27:365-72. 
17 Best C, Haseen F, Currie D, et al. Relationship between trying an electronic cigarette and subsequent cigarette experimentation in Scottish adolescents: a cohort study. Tob Control 2018;27:373-8.

18 Conner M, Grogan S, Lawton R, et al. Study protocol: a cluster randomised controlled trial of implementation intentions to reduce smoking initiation in adolescents. $B M C$ Public Health 2013;13.

19 Conner M, Grogan S, West R, et al. Effectiveness and cost-effectiveness of repeated implementation intention formation plus anti-smoking messages on adolescent smoking initiation: a cluster randomized controlled trial. J Consulting and Clinical Psych in press.

20 Gollwitzer PM, Sheeran P. Implementation intentions and goal achievement: a metaanalysis of effects and processes. Adv Exp Soc Psychol 2006;38:69-119.

21 Conner M, Higgins AR. Long-term effects of implementation intentions on prevention of smoking uptake among adolescents: a cluster randomized controlled trial. Health Psychology 2010;29:529-38.

22 Higgins A, Conner M. Understanding adolescent smoking: the role of the theory of planned behaviour and implementation intentions. Psychology, Health \& Medicine 2003;8:173-86

23 Jarvis L. Smoking among secondary school children in 1996: England. London: HMSO, 1997.

24 Stookey GK, Katz BP, Olson BL, Olson CA, et al. Evaluation of biochemical validation measures in determination of smoking status. J Dent Res 1987;66:1597-601.

25 Jarvis MJ, Tunstall-Pedoe $\mathrm{H}$, Feyerabend C, et al. Comparison of tests used to distinguish smokers from nonsmokers. Am J Public Health 1987;77:1435-8.

26 Boyce $\mathrm{W}$, Torsheim T, Currie $\mathrm{C}$, et al. The family affluence Scale as a measure of national wealth: validation of an adolescent self-report measure. Soc Indic Res 2006;78:473-87.
27 Croxford L. Is Free-Meal entitlement a valid measure of school intake characteristics? Educational Research and Evaluation 2000:6:317-35.

28 Cloninger C, Przybeck T, Syrakic D, et al. The Temperament and Character Inventory (TCI): A guide to its development and use. St Louise. MO: Center for Psychobiology of Personality, 1994.

29 Raudenbush SW, Bryk AS. Hierarchical linear models: Applications and data analysis methods. London: Sage.

30 Soneji S, Barrington-Trimis JL, Wills TA, et al. Association between initial use of E-cigarettes and subsequent cigarette smoking among adolescents and young adults. JAMA Pediatr 2017;171:788-97.

31 Barrington-Trimis JL, Urman R, Berhane K, et al. E-cigarettes and future cigarette use. PEDIATRICS 2016;138.

32 Bauld L, MacKintosh A, Eastwood B, et al. Young People's Use of E-Cigarettes across the United Kingdom: Findings from Five Surveys 2015-2017. IJERPH 2017:14:973-84

33 Hallingberg B, Maynard OM, Bauld L, et al. Have e-cigarettes renormalised or displaced youth smoking? Results of a segmented regression analysis of repeated cross sectional survey data in England, Scotland and Wales. Tob Control 2020:29:207-16.

34 Medicine and Healthcare Products Regulatory Agency. E-cigarettes: regulations for consumer products (UK government). Available: https://www.gov.uk/guidance/ecigarettes-regulations-for-consumer-products [Accessed 7 Dec 2018]

35 Petrescu DC, Vasiljevic M, Pepper JK, et al. What is the impact of e-cigarette adverts on children's perceptions of tobacco smoking? An experimental study. Tob Control 2017; 26:421-7.

36 Wagener TL, Floyd EL, Stepanov I, et al. Have combustible cigarettes Met their match? the nicotine delivery profiles and harmful constituent exposures of second-generation and third-generation electronic cigarette users. Tob Control 2017;26:e23-8. 